\title{
Reflections on the 2019 Nobel Memorial Prize Awarded to Banerjee, Duflo, and Kremer
}

\author{
CHIARA LISCIANDRA \\ University of Groningen
}

\section{INTRODUCTION}

The Royal Swedish Academy of Sciences awarded the 2019 Sveriges Riksbank Prize in Economic Sciences in Memory of Alfred Nobel to Abhijit Banerjee, Esther Duflo, and Michael Kremer for their "experimental approach to alleviating global poverty" (Royal Swedish Academy of Sciences 2019a). As soon as the news was released, it sparked a debate among economists, international development scholars and academics in general, which has been covered in the media in the following weeks. ${ }^{1}$

Even before this year's Nobel Prize, important points concerning the research program in development economics had already been raised. The debate dates back roughly two decades, when randomized field experiments started gaining momentum. Topics range from the different levels of analysis of poverty (Cohen and Easterly 2009), to methodological and ethical issues in randomized field experiments (Deaton 2009; Rodrik 2009), to the relation between economic research and policy (Duflo 2019). The debate is broad and has prompted economists to take a stance on foundational issues regarding the methods and purpose of research in development economics. It gives all of us interested in economic methodology a wonderful opportunity to plumb economists' motivations underlying their approach to the subject. This year's award has revived previous discussion and has also added to it the question of the significance of this Nobel Prize, or rather, which particular aspects of this research program made it deserve a Nobel Prize. Given that this article is a reflection on the Nobel award, let me start from some considerations about the Nobel Prize in economics more broadly and then move to the features of this year's award.

\footnotetext{
${ }^{1}$ See, for example, Ingrid Harvold Kvangraven (2019), and Sanjay Reddy (2019).
} 


\section{CRITERIA FOR A NOBEL}

Broadly speaking, what are the criteria that make a piece of research in economics worth a Nobel Prize? The Nobel committee does not have a list of criteria set in stone, but Assar Lindbeck-the chairman of the Prize Committee from 1980 to 1994-provided some indications in an overview article first published on the thirtieth anniversary of the Nobel Prize in economics:

When considering what should be regarded as a 'worthy' contribution, it is probably correct to say that the selection committee has looked, in particular, at the originality of the contribution, its scientific and practical importance, and its impact on scientific work. [...] To some extent, the committee has also considered the impact on society at large, including the impact on public policy. (Lindbeck 2007; italics added)

In the following sections, I will assess the laureates' contributions against the criteria given by Lindbeck. Does the laureates' work meet the requirement for a Nobel Prize? Do the critics contend that they don't? As it will become clearer as this paper unfolds, while there is a general consensus that at least some criteria have been met by the awardees, critics are divided on whether the laureates are deserving of the award.

\section{THE DeBATE}

That this Nobel Prize has generated controversy has struck many as surprising. There are, in fact, some clear reasons for being in favour of the committee's decision. First, the laureates work on the economics of poverty and this year's Prize directs attention to the persistence of poverty in the world. The awardees' research focuses on topics including education, health, micro-credit, gender, and policy effectiveness in developing countries. It is estimated that, in less than two decades, the Poverty Action Lab-which supports most of the laureates' development projects-reached up to 400 million people worldwide. Moreover, this Nobel award has a symbolic significance: Banerjee is one of the few laureates from a non-Western country to receive a Nobel Prize in economics, and Duflo is the second female and the youngest laureate in economics since the award was established 50 years ago. Note that, in economics, the average age for being considered for a Nobel prize is around 65. The average age of this year's awardees is 53 (Royal Swedish Academy of Sciences 2020). 
As Uskali Mäki pointed out (2019), there is something striking about the Nobel being assigned to young scholars and to a field that is so recent in terms of research time. ${ }^{2}$ Kremer started writing on education in the nineties and, soon thereafter, Duflo and Banerjee followed. On the one hand, it is remarkable that the work of young scholars has been recognized very early in time. The laureates must have been courageous enough to start a new line of research that probably was not aligned with the standards of their discipline and their scientific community.

On the other hand, it is precisely because so little time has passed since the first studies were published that it might be too early to clearly assess the reliability and generalizability of the results. It was exactly on this point that Lindbeck wrote in the same article quoted above:

When deciding who should be regarded as worthy of a Prize, the scrutiny of time has helped the committee considerably. [...] [I]t usually takes a longer time in economics (and social sciences in general) than in the natural sciences to find out if a new contribution is solid or if it is just a fad. [...] The reason is not only that economic behavior, like human behavior in general, is complex but also that it varies over time and place. [...] Thus, new results may turn out to be relevant only to a transient conjuncture of circumstances, having much less generality than was supposed at first. (Lindbeck 2007; italics added)

These words couldn't be more at odds with this year's award. ${ }^{3}$ The committee's decision for an 'early Prize' might indicate that these days the pace of scientific research-or at least of certain research programs-is faster as compared to when Lindbeck wrote his article. Even so, a shift towards young researchers may come with some drawbacks. It might reinforce an increasing tendency to push scholars to establish themselves at a very young stage of their career, to publish quickly, to present their results as novel and ground-breaking, and, more generally, to make bold claims about their findings and outputs (Mäki 2019). As we will see in section 5 , it is this critical attitude towards the possibilities of microdevelopment economics that the critics of the laureates often advocate,

\footnotetext{
${ }^{2}$ Note that there are awards in economics that are specifically targeted to young scientists. The John Bates Clark Medal, for instance, is awarded to economists under the age of 40. This medal is usually considered to be the antechamber of a Nobel Prize, something which clearly suggests that the Nobel is usually meant for later contributions (Cherrier and Svorenčík 2020).

${ }^{3}$ Note, however, that Lindbeck also adds that early Prizes can be given to particularly important contributions.
} 
as well as the need to put randomized control trials (RCTs) into their proper perspective.

\section{ORIGINALITY OF THE CONTRIBUTION AND IMPACT ON SCIENTIFIC WORK}

What about originality and impact? The Nobel committee report states that: "the empirical microeconomic approach pioneered by Banerjee, Duflo and Kremer has changed how development economists conduct their research" (Royal Swedish Academy of Sciences 2019b, 34). They started a revolution-a quiet revolution in their own words-in the field of development economics by pioneering the use of randomized field experiments. Even though there is previous work in labor economics that uses RCTs, the 'randomistas'-as Angus Deaton has called the laureatesmade RCTs the standard of this research program.

How have RCTs revolutionized development economics? First, they introduced the possibility to run experiments with participants in their everyday settings. Field experiments with real subjects were not in the toolkit of economic analysis before. The first steps towards experimental analysis were taken before the advent of RCTs, when laboratory experiments entered economics. Field experiments moved the stage from the laboratory to the field. ${ }^{4}$ Moreover, the new method brought with it novel research questions. This is also because the core issues of macrodevelopment economics-such as trade, monetary and fiscal policy, industrialization-cannot be tackled via RCTs. With a new method, the focus of development economics has also shifted to original questions that weren't systematically addressed before.

Concerning the impact on scientific work, it is attested that over the last years, there has been a significant increase in publications based on RCTs. Between 2000 to 2015, five top economic journals (American Economic Review, The Quarterly Journal of Economics, Econometrica, The Review of Economic Studies, and Journal of Political Economy) have increased publications of papers in development economics that are based on RCTs (Banerjee, Duflo, and Kremer 2016). In a review of impact evaluation studies in international development between 1981 and 2012, Cameron and collaborators (2016) show that the majority are based on RCTs. In development economics journals, the impression is that the relevance of RCTs is such that it might be a prerequisite for a publication

\footnotetext{
${ }^{4}$ For a comparison between randomized field experiments and laboratory experiments in economics, see Nagatsu and Favereau (2020).
} 
(Lensink 2019). Finally, new generations of economists have been inspired by the randomistas and are enthusiastic about the promises of the field.

The laureates acknowledge the collaborative nature of their projects and each of them has stressed this feature in their Nobel lecture. Esther Duflo began her speech saying, "this is a prize for a movement" (2019). Banerjee thanked the "entire community of randomistas" (2019), and Kremer (2019) talked about the next questions that the movement will address. The echo of this research program has been indeed quite remarkable. At the same time, the dark side of this result is that RCTs are becoming so dominant that they risk to mask other methodological approaches that could rather complement them. This is, in fact, one of the worries that has been raised by, among others, macro-development economists (Deaton 2009, 2010; Rodrik 2009); a worry that has been vocally expressed before and after the Nobel award. In the next section, I will briefly present this critique and the arguments supporting it.

\section{SCIENTIFIC AND PRACTICAL IMPORTANCE,}

\section{AND IMPACT ON PUBLIC POLICY: WHAT IS AN RCT?}

The main point of the methodological debate on micro-development economics concerns the potential and limitations of RCTs. Very briefly, field experiments in economics predominantly use randomized controlled trials. RCTs are based on the simple idea of testing an intervention over a randomly chosen treatment group and a control group. The aim of randomization is to compare two (or more) groups that are statistically interchangeable with each other-in other words, where the factors that might affect the intervention have the same probability distribution. This way, if the intervention produces a certain effect in the treatment group, but not in the control group, we can infer that the effect was caused by the treatment and not by other differences between the groups. In doing so, RCTs prevent possible selection biases that might otherwise undermine the result.

RCTs are commonly used in medicine for testing drugs. Banerjee, Duflo, and Kremer have transferred this methodology from the medical sciences to the social sciences, and use them to address questions in a variety of domains. ${ }^{5}$ In the context of education, for instance, RCTs analyze the impact of infrastructures on school quality, of students'

\footnotetext{
${ }^{5}$ For a comparison between randomized control trials in the medical sciences and in the social sciences, see Favereau (2016).
} 
absenteeism and teachers' effort on test scores; in the context of health, the laureates have conducted experiments on-among other thingsimmunization, deworming, and the effect of subsidies on health products (see, for example, Banerjee et al. 2007; Duflo, Dupas, and Kremer 2011; Glewwe, Kremer, and Moulin 2009; Kremer 2003; and Miguel and Kremer 2004).

The rise of RCTs has determined an increased focus on identification strategies for inferring causal effects. Yet, the results of RCTs are often cautionary tales rather than success stories. ${ }^{6}$ They show that, contrary to what it might be thought, providing more resources to schools-such as textbooks or flip charts-has limited positive impact on school quality. They also show that reducing student absenteeism does not necessarily improve test scores; and, that providing free access to health products does not reduce their use, as even low fees can significantly reduce uptake.

\section{SOME LIMITATIONS OF RCTS}

RCTs are a powerful method of tackling questions such as those listed above and many more. But, as with all research methods, they also come with their limitations. The contention of most critics is that RCTs are not the gold standard that provides hard evidence for the hypothesis under study (Deaton 2010; Rodrik 2009). ${ }^{7}$ At times, however, the randomistas tend to assign a privileged status to RCTs over other empirical methods of analysis, such as macro-studies based on cross-country regressions or panel data. According to Banerjee:

When we talk of hard evidence, we will therefore have in mind evidence from a randomized experiment, or, failing that, evidence from a true natural experiment, in which an accident of history creates a setting that mimics a randomized trial. $(2007,12)$

According to other scholars, however, RCTs are not on a better footing than other methods of scientific inquiry. For instance, Dani Rodrik wrote:

\footnotetext{
${ }^{6}$ In fact, most of the times, RCTs give null results, which also explains why RCTs- contrary to what is commonly held, even by the Nobel committee-are not very popular among policy-makers, who are rather after positive effects that might justify government funding.

${ }^{7}$ Deaton is quite direct on this point: "Randomization is not a gold standard because 'there is no gold standard' [...]. Randomized controlled trials cannot automatically trump other evidence, they do not occupy any special place in some hierarchy of evidence, nor does it make sense to refer to them as 'hard' while other methods are 'soft'” $(2010,426)$.
} 
Randomized evaluations do pretty well when they are targeted closely at the policy change under consideration, but less so when they require considerable extrapolation. In the latter case, evidence from randomized field experiments need not be more informative than other types of evidence which may have less airtight causal identification but are stronger on external validity (because of broader geographical or temporal coverage). $(2009,27)$

What are some of the main issues that RCTs face, beyond those that Rodrik mentions? To start with, one of the problems is the assumption that randomization creates groups that are statistically identical. It is true that, if the number of individuals in the experimental groups goes to infinity, then the probability of confounding factors is indeed equally distributed. However, groups have a potentially small, finite number of members, depending on the experiment in question and the budget available. It is thus possible that, even via randomization, we get groups that differ from each other for features that affect the experiment. Expert judgment may then be useful to recognize possible flaws in the experimental procedure. Expert judgment, however, can at most intervene when confounding factors are manifest, but not on unknown factors. However, the point of randomization is to allow experimenters to control indirectly for both observable and unobservable variables. In other words, expert judgment is precisely what would deny RCTs the pretense of scientific rigour, for which their use was first advocated (Reiss 2013; Rodrik 2009).

A further criticism is that, even though RCTs provide evidence of effectiveness, they do not provide evidence of causal mechanisms (Deaton 2010; Labrousse 2016). This is the sense in which they have been compared to the black boxes of experimental analysis: they typically lack an underlying theory or model that provides an explanation of the phenomenon under study. By means of an RCT we might get to know that something works (or not), but we do not know why and how.

In the context of policy, knowledge of mechanisms is often crucial insofar as it gives policy-makers an indication of where to intervene to achieve the desired outcome. As a matter of fact, the same policy might have different implications, depending on the mechanism that brings about a certain behavior. To illustrate this: suppose that, upon running an RCT, we find out that people take bed nets when they are given for free but not if there is a small fee to pay. ${ }^{8}$ Suppose also that we had two

\footnotetext{
${ }^{8}$ The example is taken from Cohen and Easterly (2009).
} 
(or more) hypotheses for why people do not buy bed nets, even at a low price: either because of present bias or because they lack information about how bed nets work and what they are for. The same policy of giving bed nets for free to prevent malaria would work under the first hypothesis, but not under the second. In the latter scenario, it would be no use to give bed nets for free, since people might use them for other things than preventing malaria, such as-as anecdotal evidence reportsfor fishing or as wedding veils.

A further issue concerns the problem of external validity of RCTs (Deaton 2009; Rodrik 2009). Even though field experiments are conducted in the wild, this does not mean that they are immune from problems of extrapolation. Knowing that something works in a specific country at a given time does not allow one to infer that it will work somewhere else in the future. As Nagatsu and Favereau (2020) note, it is misleading to think that RCTs are better suited to address problems of external validity than laboratory experiments. RCTs have a different genealogy than laboratory experiments, they were introduced in economics to assess development policy aids, not to address external validity problems. As compared to the laboratory, RCTs may be less artificial, but making something less artificial does not necessarily make it more generalizable.

Overall, the controversy over RCTs reflects a more general tension between macro-approaches and micro-approaches to development economics, a difference that is often expressed in terms of 'thinking big versus thinking small'. The approach of the laureates is to tackle poverty by breaking it down into a number of smaller, specific questions about health, education, micro-credit, etc. It has been asked whether, by doing so, they are shifting the focus away from the big questions that concern the broad economic system that perpetuates global poverty.

Thinking small has recently been used in a negative fashion, often together with labels such as impoverished economics or the poverty of poor economics, to convey the idea that the laureates 'aim too low on global poverty'. Originally, however, the idea of 'thinking small' had a more constructive connotation. It derived from a turn in development economics following a widespread skepticism about macroeconomic solutions to development problems. Cohen and Easterly talk about "the collapse of 'thinking big'” $(2009,2)$ to refer to a series of uncertain results in the application of macroeconomic policy in developing countries. One standard example is the 'Washington Consensus', a set of policy prescriptions for developing countries, whose results turned out to be 
either not as successful as it was hoped or anyway difficult to evaluate (Ravallion 2009).

As a reaction to this 'crisis', 'thinking small' indicated a more pragmatic, effective and goal-oriented approach to development problems. Advocates of this approach claim that this is the strategy to follow as there are no definite answers to big questions such as: What is the cause of poverty, of growth and development? Economics makes progress little by little, step by step, as any other science does.

This clearly does not mean that the macro-development approach has been neglected-although its relevance has at times been downplayed by the opposite camp. Issues such as the role of structural transformations, international economic integration, and the role of distorted markets are still central (Inklaar 2019). For instance, one of the main goals of the current research agenda concerns the outline of a theoretical framework for measurement purposes. Such a framework would allow us to measure, among other things, world poverty; to construct a global poverty line; and to establish how to update it (Deaton 2010).

These goals are clearly related to the research of this year's laureates. But the challenges behind such goals make it clear that, at the moment, our understanding of poverty, growth and development is riddled with uncertainty. We do not yet know what is the best way of defining world poverty and we do not yet know what has determined a sustained decrease in world poverty, however we define it, over the last decades. In light of this, the motivation behind this year's Nobel Prize, which is that the laureates' findings reduce or mitigate global poverty, seems to be unwarranted.

That said, a more charitable interpretation of the Nobel committee's statement is possible. The laureates ask questions such as, how can we make sure that pregnant mothers sleep under bed nets? Or, how can we make sure that farmers use improved seeds or fertilizer? If we take a broader interpretation of the determinants of wealth, which include factors such as health, nutrition and education, then it appears clear that the work of the laureates has contributed to an increase of human and social capital by helping children and people worldwide, for instance, by reducing worming in affected regions or by devising successful school programs. 


\section{THE ETHICS OF RCTS}

An overview of the main topics of debate around micro-development economics cannot neglect to mention ethical considerations. One set of ethical issues that have been raised in relation to RCTs concerns experimentation with human subjects. A thorough analysis of the ethical implications of RCTs falls beyond the scope of this article, but in order to give a flavour of just some of the facets of this debate, it is helpful to start from a comparison between the research protocols that are used in economics and in medicine (Nardini 2014).

Medical doctors have strict research protocols to follow with human experimentation. These protocols provide guidelines that, among other things, help doctors to mediate between opposing professional goals, such as helping current patients versus testing new drugs in view of medical progress, or deciding who should receive a treatment at the expense of others, also in light of possible drawbacks. Similar ethical dilemmas clearly emerge in the context of development economics, but it seems that they have not been as strictly addressed in economics as in medicine so far.

One clear example is informed consent. Informed consent is a basic requirement for clinical RCTs: it requires that subjects have expressed their consent to participate in the experiment, that they are competent subjects and express their consent voluntarily; it also requires that they have been adequately informed about the purpose of the research and about the risks and benefits involved. ${ }^{9}$

In a recent paper, Hoffmann (2020) draws on a set of RCTs papers that have been published in top economic journals between 2009 and 2014. According to her analysis, informed consent tends to be discussed in the majority of the studies that took place in Europe and the United States. However, only $10 \%$ of those that were conducted in Africa, Asia, and Latin America indicated informed consent. This clearly shows that there are differences in ethical standards depending on the country where the study takes place.

Another example is equipoise, which refers to the situation where medical doctors are genuinely uncertain about the potential and drawbacks of the treatment they administer. This is considered to be a

\footnotetext{
${ }^{9}$ Clearly, both in medicine and in development economics, it is far from trivial what constitutes an adequate level of information, i.e. at what level of detail the research project should be presented, something which is particularly problematic in case of vulnerable subjects such as the ill or the poor.
} 
requirement in clinical trials. The reason is that, if both the control group and the treatment group face the same probability of a positive outcome, then the medical doctor is not favouring one group over the other, nor denying the participants the possibility of, in principle, receiving the best possible care available. But as Abramowicz and Szafarz (2020) show, equipoise is typically ignored in development economics and there is an entire debate about whether the scarcity of resources justifies this practice. Overall, difficult ethical questions arise in the context of human experimentation. In the same way as bioethicists work together with medical doctors to define their operating guidelines, ethicists might equip development economists with tools that could help them make difficult decisions in experimental contexts.

Beyond the specific issues related to RCTs, ethics comes into play when considering the impact of the laureates' work on societal and policy issues. The matter is also intricate, partly because it is not always completely clear how to position the role of the awardees in relation to policy: on the one hand, they describe themselves as genuine scientists, or 'plumbers'-to follow Duflo's metaphor-who run RCTs according to rigorous standards of experimentation. This way, they would remain outside of the domain of ethics and all of the intricacies that it entails. On the other hand, they also claim to pursue goals-such as fighting global poverty - that are political in nature and that, as such, open up a whole set of ethical issues.

At first sight, it might even be thought that there are not many ethical implications to discuss here, because health and primary education are basic universal human rights. But beyond that, a large part of microdevelopment economics is about running RCTs to find out how to stimulate the economy in a certain region or for a group of people. Microfinance, for instance, studies financial tools, such as loans to poor borrowers who wouldn't normally fulfil the eligibility criteria that banks typically require. Other programs basically inject cash in an economy to stimulate economic growth to increase investments and productivity. Is enhancing economic productivity an ethical goal in itself? What changes in social structures should be instantiated for economic policies to be successful? And what is the normative framework that justifies such interventions? Though controversial, these are important issues for scientists working in political contexts to consider. 


\section{CONCLUSION}

What can we conclude about the research program in micro-development economics with respect to the criteria for a Nobel Prize? This year, the Nobel Prize has been awarded to a research program in economics that is strongly experimentally driven, draws heavily on statistics, and is far away from a rigorous theoretical framework. At the opposite end of the spectrum we find, for instance, contributions to general equilibrium theory, which have also attracted several Nobel Prizes before, such as Paul Samuelson (in 1970), Kenneth Arrow (1972), Gérard Debreu (1983), among others. The empirical approach in economics has been prompted by the so-called "credibility revolution", which, as the Nobel report of this year's award says, "pushed economic research in several areas towards a stronger focus on estimating causal effects" (Royal Swedish Academy of Sciences 2019b, 2). Other Nobel Prizes that reflect similar considerations are, for instance, Richard Thaler (in 2017), Robert Schiller (2013), Daniel Kahneman (2002), Vernon L. Smith (2002), and Herbert Simon (1978). Even more so than in previous years, the work of Banerjee, Duflo, and Kremer is strongly inductive and pursues research beyond academic boundaries, collaborating with governments, NGOs, local collaborators, business partners, and policy-makers.

In this article, I have suggested that the laureates' work fits the bill with respect to originality, impact on scientific work and, at least in part, public policy. On the other hand, however, there are no compelling reasons to endorse the motivation the committee provided to describe the scientific achievements of the laureates. But it might be too early for a conclusive answer: as the committee already pointed out, the scrutiny of time might be required to let science run its course.

\section{REFERENCES}

Abramowicz, Michel, and Ariane Szafarz. 2020. "Ethics of RCTs: Should Economists Care about Equipoise?" In Randomized Control Trials in the Field of Development: A Critical Perspective, edited by Florent Bédécarrats, Isabelle Guérin, and François Roubaud. Oxford: Oxford University Press.

Banerjee, Abhijit V. 2007. Making Aid Work. With Alice H. Amsden, Robert H. Bates, Jagdish N. Bhagwati, Angus Deaton, and Nicholas Stern. Cambridge, MA: MIT Press.

Banerjee, Abhijit V. 2019. "Prize Lecture: Field Experiments and the Practice of Economics." Accessed October 22, 2019. https://www.nobelprize.org/prizes/economic-sciences/2019/banerjee/lecture/. 
Banerjee, Abhijit V., Shawn Cole, Esther Duflo, and Leigh Linden. 2007. "Remedying Education: Evidence from Two Randomized Experiments in India." The Quarterly Journal of Economics 122 (3): 1235-1264.

Banerjee, Abhijit, Esther Duflo, and Michael Kremer. 2016. "The Influence of Randomized Controlled Trials on Development Economics Research and on Development Policy." Working paper prepared for "The State of Economics, The State of the World" conference at the World Bank.

Cameron, Drew B., Anjini Mishra, and Annette N. Brown. 2016. "The Growth of Impact Evaluation for International Development: How Much Have We Learned?" Journal of Development Effectiveness 8 (1): 1-21.

Cherrier, Beatrice, and Andrej Svorenčík. 2020. "Defining Excellence: Seventy Years of the John Bates Clark Medal." Journal for the History of Economic Thought 42 (2): 153-176.

Cohen, Jessica, and William Easterly. 2009. "Introduction: Thinking Big versus Thinking Small." In What Works in Development? Thinking Big and Thinking Small, edited by Jessica Cohen, and William Easterly, 1-23. Washington, DC: Brookings Institution Press.

Deaton, Angus. 2009. "Instruments of Development: Randomization in the Tropics, and the Search for the Elusive Keys to Economic Development." NBER Working Paper No. 14690. National Bureau of Economic Research, Cambridge, MA.

Deaton, Angus. 2010. "Instruments, Randomization, and Learning about Development." Journal of Economic Literature 48 (2): 424-455.

Duflo, Esther. 2019. "Prize Lecture: Field Experiments and the Practice of Policy." Accessed October 22, 2019. https://www.nobelprize.org/prizes/economicsciences/2019/duflo/lecture/.

Duflo, Esther, Pascaline Dupas, and Michael Kremer. 2011. "Peer Effects, Teacher Incentives, and the Impact of Tracking: Evidence from a Randomized Evaluation in Kenya." American Economic Review 101 (5): 1739-1774.

Favereau, Judith. 2016. "On the Analogy Between Field Experiments in Economics and Clinical Trials in Medicine.” Journal of Economic Methodology 23 (2): 203-222.

Glewwe, Paul, Michael Kremer, and Sylvie Moulin. 2009. "Many Children Left Behind? Textbooks and Test Scores in Kenya." American Economic Journal: Applied Economics 1 (1): 112-135.

Hoffmann, Nimi. 2020. "Involuntary Experiments in Former Colonies: The Case for a Moratorium." World Development 127: 104805.

Inklaar, Robert. 2019. "A Macro Perspective on the RCT-Prize." Seminar, University of Groningen, October 2019.

Kremer, Michael. 2003. "Randomized Evaluations of Educational Programs in Developing Countries: Some Lessons.” American Economic Review 93 (2): 102-106.

Kremer, Michael. 2019. "Prize Lecture: Experimentation, Innovation, and Economics." Accessed October 22, 2019. https://www.nobelprize.org/prizes/economicsciences/2019/kremer/lecture/.

Kvangraven, Ingrid Harvold. 2019. "Impoverished Economics? Unpacking the Economics Nobel Prize." Open Democracy. Accessed October 19, 2019. https://www.opendemocracy.net/en/oureconomy/impoverished-economicsunpacking-economics-nobel-prize/.

Labrousse, Agnès. 2016. "Not by Technique Alone. A Methodological Comparison of Development Analysis with Esther Duflo and Elinor Ostrom." Journal of Institutional Economics 12 (2): 277-303. 
Lensink, Robert. 2019. “Abhijit Banerjee, Esther Duflo and Michael Kremer.” Seminar, University of Groningen, October 2019.

Lindbeck, Assar. 2007. "The Sveriges Riksbank Prize in Economic Sciences in Memory of Alfred Nobel 1969-2007." NobelPrize.org. Accessed June 23, 2020. https://www.nobelprize.org/prizes/themes/the-sveriges-riksbank-prize-in-economic-sciences-inmemory-of-alfred-nobel-1969-2007-2.

Mäki, Uskali. 2019. “What's Worth a Nobel Prize?” Lecture, University of Helsinki, November 2019.

Miguel, Edward, and Michael Kremer. 2004. "Worms: Identifying Impacts on Education and Health in the Presence of Treatment Externalities." Econometrica 72 (1): 159217.

Nagatsu, Michiru, and Judith Favereau. 2020. "Two Strands of Field Experiments in Economics: A Historical-Methodological Analysis." Philosophy of the Social Sciences 50 (1): 45-77.

Nardini, Cecilia. 2014. "The Ethics of Clinical Trials.” Ecancermedicalscience 8: 387.

Ravallion, Martin. 2009. "Comment." In What Works in Development? Thinking Big and Thinking Small, edited by Jessica Cohen, and William Easterly, 51-54. Washington, DC: Brookings Institution Press.

Reddy, Sanjay G. 2019. “Economics’ Biggest Success Story Is a Cautionary Tale.” Foreign $\begin{array}{llll}\text { Policy. } & \text { Accessed } & \text { October } & 22,\end{array}$ https://foreignpolicy.com/2019/10/22/economics-development-rcts-esther-dufloabhijit-banerjee-michael-kremer-nobel/.

Reiss, Julian. 2013. Philosophy of Economics: A Contemporary Introduction. New York, NY: Routledge.

Rodrik, Dani. 2009. "The New Development Economics: We Shall Experiment, but How Shall We Learn?" In What Works in Development? Thinking Big and Thinking Small, edited by Jessica Cohen, and William Easterly, 24-47. Washington, DC: Brookings Institution Press.

Royal Swedish Academy of Sciences. 2019a. "Press Release: The Prize in Economic Sciences 2019.” Nobelprize.org. Accessed October 22, 2019. https://www.nobelprize.org/prizes/economic-sciences/2019/press-release/.

Royal Swedish Academy of Sciences. 2019b. "Scientific Background on the Sveriges Riksbank Prize in Economic Sciences in Memory of Alfred Nobel 2019: Understanding Development and Poverty Alleviation." Nobelprize.org. Accessed October 22, 2019. https://www.nobelprize.org/uploads/2019/10/advancedeconomicsciencesprize2019.pdf.

Royal Swedish Academy of Sciences. 2020. "Nobel Laureates by Age." NobelPrize.org. Accessed October 22, 2019. https://www.nobelprize.org/prizes/lists/nobellaureates-by-age.

Chiara Lisciandra is Assistant Professor at the University of Groningen, Faculty of Economics and Business. She is a board member of the Centre for Philosophy, Politics and Economics at the University of Groningen, and an elected board member of the International Network for Economic Method. Her primary research interests are in general philosophy of science, philosophy of economics, and social philosophy.

Contact e-mail: <c.lisciandra@rug.nl>

Website: <www.chiaralisciandra.com> 